\title{
Socio-Demographic Characteristics of Mentally ill Patients Admitted to Different Hospitals of Dhaka City
}

\author{
Hakim $\mathrm{M}^{1}$, Airin $\mathrm{J}^{2}$, Naher $\mathrm{S}^{3}$, Ali $\mathrm{M}^{4}$, Ahmad $\mathrm{M}^{5}$, Al-Azad MAS ${ }^{6}$
}

\begin{abstract}
Introduction: Mental health is essentially as important as the physical health required of an individual to maintain. There are many factors that seem to play a role in the genesis of mental illness.

Objective: This study was conducted among the mentally ill patients admitted to four hospitals of Dhaka city with a view to find out their socio demographic characteristics of mental illness.
\end{abstract}

Materials and Methods: It was a descriptive type of cross sectional study. A total number of 81 patients and their near relatives were interviewed at four medical institutions through a structured questionnaire. A checklist was used for clinical diagnosis of the patients. A master sheet was prepared followed by questionnaire plotting all the information. Then data were analyzed according to objectives and necessary tables were prepared accordingly by case appropriate variables of the study using Microsoft office program.

Results: The study results showed that $81.49 \%$ patients were male and $18.51 \%$ patients were female. Of the total patients $71.61 \%$ were found in the age group of unto 30 years. Maximum patients $(61.73 \%)$ were found within the monthly family income of BDT 2500/- to $4500 /$ - only. $53.03 \%$ of patients were married followed by $39.51 \%$ of unmarried. The study revealed that $58.02 \%$ patients hailed from urban area. $61.73 \%$ patients were educated up to secondary level and only $8.64 \%$ patients were illiterate. Regarding occupation $27.17 \%$ patients were cultivator and $16.05 \%$ were students. The study reflected that $48.15 \%$ patients were smokers and very few (6.17\%) were drug drug addicts. $61.73 \%$ patients were living in joint families.
$50.62 \%$ patients did not receive treatment prior to admission. Of the total $49.38 \%$ treated cases (prior to admission), $25 \%$ cases were treated from the homeopath and only $25 \%$ were consulted with specialist.

Conclusion: The lower and middle socio economic group and literate group from urban areas living in joint family suffered more from mental illness. There is need for appropriate policy to address the problems of families with mentally ill patients at the family and community levels.

Key-Words: Socio-Demographic characteristics, mental illness, treatment.

\begin{abstract}
Introduction
A sound mind in a sound body is the prerequisite for proper human performances. Mental health is essentially as important as the physical health required of an individual to maintain. It has been estimated on a global basis that nearly 500 million people may be suffering from some kind of mental disorder or impairment and the number will so as to 546 million by the $2000^{1}$. 3/4th of such population live in the developing countries and the fraction will be more than $4 / 5$ th by the year 2000 . Other estimates constitute $40 \%$ of disabled people owe their disability to mental disorders and $30 \%$ of all illness are due to mental illness ${ }^{2}$. The estimates of the mentally retarded and intellectually handicapped are respectively 10 to 30 and 4 per thousand and one deaths in every hundred is by suicide. ${ }^{3}$. Psychiatry has been described as the oldest art in medicine and the newest science. Prior to the development of psychiatry in the $19^{\text {th }}$ century, psychological deviance
\end{abstract}

1. Lt Col Maksumul Hakim, MBBS, MPH, M Phil (PSM), GSO-1 Trg, ARTDOC; 2. Dr. Jinnatul Airin, MBBS, MPH (RCH), Lecturer, Community Medicine, AFMC; 3. Dr. Salma Naher, MBBS, FCPS, MS, Junior Consultant, Kurmitola General Hospital, Dhaka; 4. Brig Gen Mohammad Ali, MBBS, DPH, M.Phil, Professor and Head, Dept of Community Medicine, AFMC; 5. Lt Col Mushtaq Ahmad, MBBS, DFM, MCPS, FRSPH, Assoc Prof and Head, Dept of Forensic Medicine, AFMC; 6. Lt Col Md Abdus Samad Al-Azad, MBBS, DFM, MCPS, Asst Prof of Forensic Medicine, AFMC. 
or illness was often dealt with in very inhuman ways that form an unfortunate chapter of the western history ${ }^{4}$. Mental illness is an important public health problem. Several study results. Suggest that mental health problems are increasing in the community. There are about 1.1 million people in Bangladesh who are having serious and disabling mental disorders and five to six million are suffering from psychological and psychosomatic disorders ${ }^{3}$. In Bangladesh perspective it is more important than elsewhere, because a majority of the population is prone to mental tension forced upon them by poor economic conditions, and turbulent social pressures. The impact of mental illness is felt severely in a family or an organization with the unfortunate existence of a mentally ill patient. The number of such patients in Bangladesh is not few. Previous studies indicate that more than a mission people here are suffering from serious and disabling mental disorders and five to six times of that number are affected due to psychological and psychosomatic disorders ${ }^{5}$. Large families with low monthly income, unemployment, lack of friendship or confidence, single parent families' prolonged serious illness and drug dependence are just some of the factors that seem to play a role in the genesis of mental illness. A disparity between family income and liability, unemployment, lack of friendship, appreciation, mental torture, unfulfilled fundamental needs are the factors leading to separation of family members prolonged frustration and serious illness and drug addiction are just some of the factors that contributes mainly in the development of mental illness. Just as many accidents are preventable and physical trauma treatable, so also the mental illness might be avoidable if the people in the community know more about the danger signals of approaching mental breakdown and importance of early psychiatric assistance. Socio demographic characteristics of mental illness patients are of importance in the causation of the disease. In Bangladesh perspective it is also utmost important ${ }^{4}$. The study attempts to highlight some socio economic and socio demographic characteristics of mental illness patients, which may provide some guideline for prevention of mental diseases. It is therefore imperative to undertake a study, which attempts to identify key socio-economic and socio demographic characteristics of mentally ill patients, which may help and provide proper guidelines for prevention and cure of mental diseases.

\section{Materials and methods}

It was a descriptive type of cross sectional study. To conduct these study four medical institutions were selected as the place of study- Sir Salimullah Medical College and Mitfort Hospital (SSMC and MH), Bangladesh Sheikh Mujib Medical University (BSMMU), Dhaka Medical College Hospital (DMCH) and Combined Military Hospital (CMH), Dhaka. These institutions were chosen purposively and depending upon easy communication, availability of samples and other relevant factors. The study was conducted from 25th March 2013 to $25^{\text {th }}$ June 2013. For the sake of convenience a work schedule was prepared and the tasks were accomplished accordingly. Eighty one mental cases were purposively selected as sample for this study. The first working days of weeks were selected for the collection of data from psychiatric wards of different hospitals. Thus the Sunday, Monday, Tuesday and Wednesday were selected for the collection of data from SSMC and $\mathrm{MH}, \mathrm{BSMMU}, \mathrm{DMCH}$ and $\mathrm{CMH}$ respectively.

By this way four days in each week of the months March and April 2013 were engaged in data collection from the new admitted cases. Structured questionnaire was used for the collection of data regarding socio-demographic characteristics of mentally ill patient through direct face to face interview. A check list was used to collect data regarding specific mental illness (disease). Collected data were first edited, processed and then tabulated manually to maintain firm consistency. A master sheet was prepared followed by questionnaire plotting all the information. Then data were analyzed according to objectives and necessary tables were prepared accordingly by case appropriate variables of the study using Microsoft office program.

\section{Results}

The patients were distributed by their age and sex and found that out of 81 patients, $81.49 \%$ were male and $18.51 \%$ were female. Maximum patients $(44.45 \%)$ were in the age group of 21-30 yrs. The next highest number $(27.16 \%)$ was within the age group of up to 20 years followed by $13.58 \%$ within the age group of $31-40 \mathrm{yrs} .7 .41 \%$ of patients were in the age group of 41-50 years and above. 
Table-I: Distribution of mentally ill patients by age and sex $(n=81)$.

\begin{tabular}{|l|c|c|c|c|c|c|}
\hline \multirow{2}{*}{ Age (Year) } & \multicolumn{2}{|c|}{ Male } & \multicolumn{2}{c|}{ Female } & \multicolumn{2}{c|}{ Total } \\
\cline { 2 - 7 } & No & \% & No & \% & No & \% \\
\hline Upto 20 & 17 & 20.99 & 5 & 6.17 & 22 & 27.16 \\
\hline $21-30$ & 30 & 37.04 & 6 & 7.41 & 36 & 44.45 \\
\hline $31-40$ & 9 & 11.11 & 2 & 2.47 & 11 & 13.58 \\
\hline $41-50$ & 5 & 6.17 & 1 & 1.23 & 6 & 7.40 \\
\hline Above 50 & 5 & 6.18 & 1 & 1.23 & 6 & 7.41 \\
\hline Total & $\mathbf{6 6}$ & $\mathbf{8 1 . 4 9}$ & $\mathbf{1 5}$ & $\mathbf{1 8 . 5 1}$ & $\mathbf{8 1}$ & $\mathbf{1 0 0}$ \\
\hline
\end{tabular}

Figure- 1 shows that out of 81 patients $90.12 \%$ were Muslims and $9.88 \%$ were Hindus.

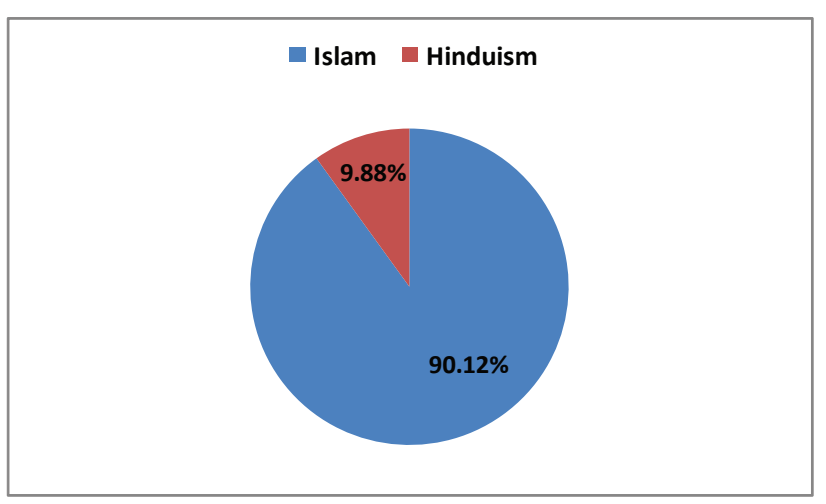

Fig-1: Distribution of mentally ill patients by religion $(n=81)$.

From the Table-II it was found that $27.17 \%$ patients were cultivators. Students were $16.05 \%$ of which $12.35 \%$ were male and $3.70 \%$ were female. The total $16.05 \%$ patients were dependent on business followed by unemployed, which comprised of $13.58 \%$. $11.11 \%$ patients were labour and $7.41 \%$ were service holder. Housewife and other group comprised of $6.17 \%$ and $2.46 \%$ respectively.

Table-II: Distribution of mentally ill patients by occupation $(\mathrm{n}=81)$.
\begin{tabular}{|l|c|c|c|c|c|c|}
\hline \multirow{2}{*}{ Occupation } & \multicolumn{2}{|c|}{ Male } & \multicolumn{2}{c|}{ Female } & \multicolumn{2}{|c|}{ Total } \\
\cline { 2 - 8 } & No & $\%$ & No & $\%$ & No & $\%$ \\
\hline Student & 10 & 12.35 & 3 & 3.70 & 13 & 16.05 \\
\hline Unemployed & 11 & 13.58 & 0 & 0 & 11 & 13.58 \\
\hline Labor & 7 & 8.64 & 2 & 2.47 & 9 & 11.11 \\
\hline Service & 6 & 7.41 & 0 & 0 & 6 & 7.41 \\
\hline Business & 13 & 16.05 & 0 & 0 & 13 & 16.05 \\
\hline Housewife & 0 & 0 & 5 & 6.17 & 5 & 6.17 \\
\hline Cultivation & 18 & 22.23 & 4 & 4.94 & 22 & 27.17 \\
\hline Others & 1 & 1.23 & 1 & 1.23 & 2 & 2.46 \\
\hline Total & $\mathbf{6 6}$ & $\mathbf{8 1 . 4 9}$ & $\mathbf{1 5}$ & $\mathbf{1 8 . 5 1}$ & $\mathbf{8 1}$ & $\mathbf{1 0 0 . 0 0}$ \\
\hline
\end{tabular}

Table-III shows that majority (35.81\%) of mental illness patients were found to have their educational qualification within secondary level and primary level comprised of $25.92 \%$ followed by higher secondary level which was $20.98 \%$ only. $8.64 \%$ patients were illiterate. $7.41 \%$ were graduate and only one patient was found postgraduate.
Table-III: Distribution of mentally ill patients by education $(n=81)$.

\begin{tabular}{|l|c|c|c|c|c|c|}
\hline \multirow{2}{*}{ Education level } & \multicolumn{2}{|c|}{ Male } & \multicolumn{2}{c|}{ Female } & \multicolumn{2}{c|}{ Total } \\
\cline { 2 - 8 } & No & $\%$ & No & $\%$ & No & $\%$ \\
\hline Illiterate & 2 & 2.47 & 5 & 6.17 & 7 & 8.64 \\
\hline Primary & 16 & 19.75 & 5 & 6.17 & 21 & 25.92 \\
\hline Secondary & 25 & 30.87 & 4 & 4.94 & 29 & 35.81 \\
\hline Higher Secondary & 16 & 19.75 & 1 & 1.23 & 17 & 20.98 \\
\hline Graduate & 6 & 7.41 & 0 & 0 & 6 & 7.47 \\
\hline Graduate+ & 1 & 1.24 & 0 & 0 & 1 & 1.24 \\
\hline Total & $\mathbf{6 6}$ & $\mathbf{8 1 . 4 9}$ & $\mathbf{1 5}$ & $\mathbf{1 8 . 5 1}$ & $\mathbf{8 1}$ & $\mathbf{1 0 0 . 0 0}$ \\
\hline
\end{tabular}

Table-IV focuses that $53.09 \%$ patients were married and $39.51 \%$ patients were unmarried. $4.94 \%$ and $2.46 \%$ were widow and divorced respectively.

Table-IV: Distribution of mentally ill patients by marital status $(n=81)$.

\begin{tabular}{|l|c|c|c|c|c|c|}
\hline \multirow{2}{*}{ Marital Status } & \multicolumn{2}{|c|}{ Male } & \multicolumn{2}{c|}{ Female } & \multicolumn{2}{c|}{ Total } \\
\cline { 2 - 7 } & No & $\%$ & No & $\%$ & No & $\%$ \\
\hline Unmarried & 27 & 33.34 & 5 & 6.17 & 32 & 39.51 \\
\hline Married & 29 & 48.15 & 4 & 4.94 & 43 & 53.09 \\
\hline Widow & 0 & 0 & 4 & 4.94 & 4 & 4.94 \\
\hline Divorce & 0 & 0 & 2 & 2.46 & 2 & 2.46 \\
\hline Total & $\mathbf{6 6}$ & $\mathbf{8 1 . 4 9}$ & $\mathbf{1 5}$ & $\mathbf{1 8 . 5 1}$ & $\mathbf{8 1}$ & $\mathbf{1 0 0 . 0 0}$ \\
\hline
\end{tabular}

Table-V shows that $19.75 \%$ patients had monthly family income below BDT 2500/-. 61.73\% patients had monthly income between BDT 2501 to BDT $4500 /-$ only. $18.52 \%$ patients had monthly family income above BDT 4500/-.

Table-V: Distribution of mentally ill patients by monthly family income.

\begin{tabular}{|l|c|c|}
\hline Monthly family income (BDT) & No of patient & Percentage \\
\hline Below 2,500/- & 16 & 19.75 \\
\hline 2500 to 4500/- & 50 & 61.73 \\
\hline Above 4500/- & 15 & 18.52 \\
\hline Total & $\mathbf{8 1}$ & 100.00 \\
\hline
\end{tabular}

Figure-2 shows that $58.02 \%$ patients were from urban area and $41.98 \%$ patients were from rural area.

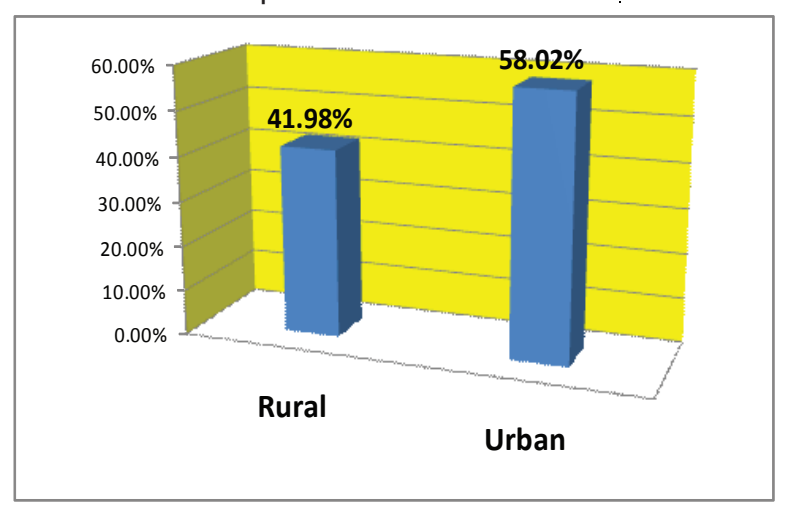

Fig-2: Distribution of mentally ill patients by place of residence $(n=81)$. 
Table-VI shows that $61.73 \%$ patients were from joint family and $30.86 \%$ patients were from single family.

Table-VI: Distribution of mentally ill patients according to their type of family $(n=81)$.

\begin{tabular}{|l|c|c|}
\hline Type of Family & Patient No & Percentage \\
\hline Single family & 25 & 30.86 \\
\hline Joint family & 50 & 61.73 \\
\hline Others & 6 & 7.41 \\
\hline Total & $\mathbf{8 1}$ & $\mathbf{1 0 0 . 0 0}$ \\
\hline
\end{tabular}

Table-VII shows that out of 81 patients, $62.96 \%$ did not receive any treatment prior to admission. $37.04 \%$ received treatment from various categories treatment providers.

Table-VII: Distribution of mentally ill patients according to treatment received prior to admission $(n=81)$.

\begin{tabular}{|l|c|c|}
\hline \multirow{2}{*}{ Response } & \multicolumn{2}{|c|}{ Treatment Received } \\
\cline { 2 - 3 } & Number & Percentage \\
\hline Yes & 30 & 37.04 \\
\hline No & 51 & 62.96 \\
\hline Total & $\mathbf{8 1}$ & 100.00 \\
\hline
\end{tabular}

Table-VIII shows that 40 patients received treatment privately prior to admission. Among them 25\% patients received treatment from homeopathy. $25 \%$ patients were treated by specialist medical officer followed by $17.50 \%$ who received treatments from MBBS doctor. $25 \%$ patients received treatment from hekim/kabiraj and traditional healers.

Table-VIII: Distribution of mentally ill patients by type of consultation received prior to admission $(n=81)$.

\begin{tabular}{|l|c|c|}
\hline Type of consultation & Number & Percentage \\
\hline Hospital & 3 & 7.50 \\
\hline Specialist & 10 & 25 \\
\hline M.B.B.S doctor & 7 & 17.50 \\
\hline Homeopath & 10 & 25 \\
\hline Hekim/Kabiraj & 5 & 12.50 \\
\hline Healers & 5 & 12.50 \\
\hline Total & $\mathbf{4 0}$ & 100.00 \\
\hline
\end{tabular}

Table-IX shows that $48.15 \%$ patients had habit of smoking. $37.04 \%$ patients gave history of nothing -special habit. $6.17 \%$ patients gave history of intake of drugs. Only 3.70\% patients were found alcoholic.
Table-IX: Distribution of mentally ill patients by personal habit $(\mathrm{n}=81)$.

\begin{tabular}{|l|c|c|}
\hline Personal Habit & No. of cases & Percentage \\
\hline Nothing special & 30 & 37.04 \\
\hline Smoking & 39 & 48.15 \\
\hline Alcohol & 3 & 3.70 \\
\hline Drugs & 5 & 6.17 \\
\hline Others (Specific) & 4 & 4.94 \\
\hline Total & $\mathbf{8 1}$ & $\mathbf{1 0 0 . 0 0}$ \\
\hline
\end{tabular}

Table-X shows that out of 81 patients 20.99\% patients mentioned previous mental injury and $79.01 \%$ patients gave no history regarding previous contributory factors for the causation of mental illness.

Table-X: Distribution of mentally ill patients by history of previous mental injury prior to admission $(n=81)$.

\begin{tabular}{|l|c|c|}
\hline \multirow{2}{*}{ Response } & \multicolumn{2}{|c|}{ Previous mental injury } \\
\cline { 2 - 3 } & Number & Percentage \\
\hline Yes & 17 & 20.99 \\
\hline No & 64 & 79.01 \\
\hline Total & $\mathbf{8 1}$ & $\mathbf{1 0 0 . 0 0}$ \\
\hline
\end{tabular}

Fig-3 shows the pattern of mental illness. It was found that schizophrenia was the most common $(54.32 \%)$ illness among admitted patients. The second highest number of patients included the heading of manic depressive psychosis (MDP) which was $17.28 \%$. Third commonest (8.64\%) illness was hysteric conversion reaction (HCR). Anxiety neurosis, atypical psychosis and obsessive neurosis comprised of $6.17 \%, 6.17 \%$ and $2.47 \%$ respectively.

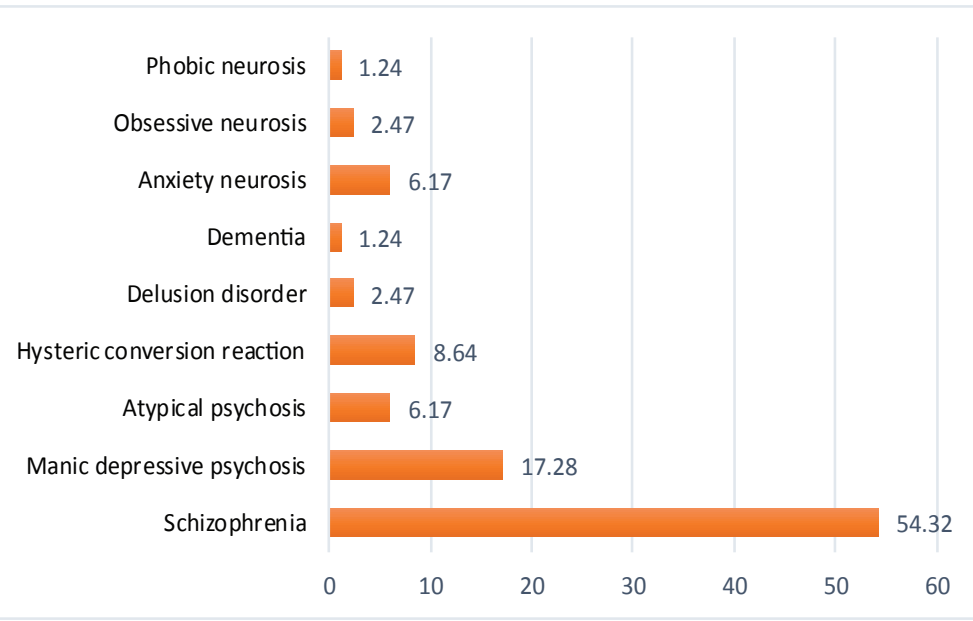

Fig-3: Type of mental diseases suffered by the admitted patients $(\mathrm{n}=81)$. 


\section{Discussion}

Mental illness has been considered as one of the major public health problems in Bangladesh. People of all ages and both sexes are sufferer of mental illness7. In this study majority $(81.49 \%)$ of patients were male (Table-I). This is because bed distributions for female patients in these hospitals were less than male. In SSMC bed allocated for male and female ward is 17 and 10 respectively and in BSMMU it is 15 and 10 respectively. In addition to that, male patients were more in number than the female too, may be due to our socio-economic condition where income of the family mainly also the unusual behavior which is tolerated less in males than females. In this study $44.45 \%$ of patients were found to be in the age group of 21 to 30 years (Table-1). This result is consistence to the study findings of Chowdhury A.K.M.N et al ${ }^{8}$.

The majorities (90.12\%) of patients were Muslim and $9.88 \%$ patients were Hindu (Fig-1). It may be stated that Muslims are more sufferers of mental illness than Hindus. This variation may be due to our demographic pattern because Muslims are the majority populating in Bangladesh (About $90 \%)^{9}$. Regarding occupation of the respondents $27.17 \%$ of patients were dependent on agriculture and 16.05\% were student followed by businessmen which was about $16.05 \%$ (Table-II). This study result is not similar to the study findings of Firoz A.H.M. et all which showed highest percentage $(23.48 \%)$ were unemployed and suffered from schizophrenia ${ }^{10}$. Majority (91.36\%) of patients were literate (Table-III) although the literacy rate of the country is very low. This result reflects that occurrence of mental illness among literate, because these people has more scope to expose different predisposing related conditions. This study is also similar to the study of Islam $\mathrm{H}^{11}$ and to the study of Karim ME et $\mathrm{al}^{12}$. The high percentage of literacy rate may also be due to localization of these four hospitals in the urban area. In this study, $53,09 \%$ of the patient were married and among them $48.15 \%$ were male and $4.94 \%$ were female. $39.51 \mid \%$ of the patients was unmarried (Table-IV). The percentage of married male and female patients of this study is not similar to the study of Islam $\mathrm{H}^{11}$. Majority $(81.48 \%)$ of cases had their monthly family income within BDT 4500/-. About $19.75 \%$ cases reported their income within BDT 2500/- (Table-V). Hence it can be concluded that most of the mentally ill patients in the study were from lower and middle class family. This finding is consistent with the study of Islam $\mathrm{H}^{11}$ and with the study of Karim ME et $\mathrm{al}^{12}$ which showed that more patients from lower and middle class came for treatment in comparison to upper class. Poor housing, financial difficulties and unemployment could act as stress factor in susceptible individuals to precipitate the disorder. $58.02 \%$ patients of this study lived in urban areas and the rest $41.98 \%$ lived in rural areas (Fig-2). These findings are somewhat unusual in comparison with the urban rural distribution of the population where $90 \%$ of our people live in the villages. The highest number of patients seeks treatment form urban areas may be due to better health consciousness, better information and easy accessibility to the hospitals. But the study of Islam $\mathrm{H}^{11}$ showed more patients from rural areas. The study of Firoz A.H.M. et al ${ }^{10}$ and Karim ME et $\mathrm{al}^{12}$ showed more patients from urban areas which is consistent with this study. This study finding showed that $61.73 \%$ patients came from joint family followed by $30.86 \%$ form single family (Table-VI). In the study $37.04 \%$ of patients received treatment prior to admission into hospitals and $62.96 \%$ patients did not receive any treatment previously (Table-VII). Twenty five percent patients were treated by homeopathy and $25 \%$ received treatment from specialist medical officer (Table-VIII). Personal habits of patients identified that $48.95 \%$ had habit of smoking followed by $37.04 \%$ who had nothing special habit. $3.70 \%$ and $4.94 \%$ patients were used to take drinks and drugs respectively (Table-IX).

$20.99 \%$ patients gave history of previous mental injury prior to admission but $79.01 \%$ gave no history of previous mental injury (Table-X). This study result showed that schizophrenia was the most common (54.32\%) illness. The second height (17.28\%) number was manic depressive psychosis. HCR and anxiety neurosis comprised $8.64 \%$ and 6.17 respectively (Fig-3). This finding is consistent with the study finding of islam $\mathrm{H}^{11}$ which showed that schizophrenia and affective disorder formed the main bulk of his study population. This study result is also consistent with the study finding of Firoz A. H. M et al ${ }^{10}$. The study of Ahmed S. $U^{13}$ revealed that schizophrenia was the commonest group (30\%) followed by affective disorder (25\%) and anxiety neurosis $(22 \%)$ which is also consistent with this study. The occurrence of schizophrenia is more 
because it is seen that at any time about $0.25 \%$ to $0.5 \%$ of the population suffers from schizophrenia and schizophrenic patients comprise about $20 \%$ of all patients in mental health facilities. In Bangladesh the same rates of prevalence also exist. In our country environment factors like stressful life events, personal, familial and social problems play and important part in causing schizophrenia in addition to genetic factors and biological factors ${ }^{14}$.

\section{Conclusion}

The study revealed that mental illness is a disorder mainly of the young adults, male predominating and relatively urban patients over represented; majority were Muslims and most of the patients were married, live in joint family, having agricultural background. More number of patients came from the middle class; paradoxically literacy rate was higher in the patients studied than in general population. Majority did not give previous history of mental injury and did not receive any treatment from any care providers prior to admission into hospitals.

It is found from the study that psychotic group admitted in the hospital in more number than the neurotic group. Among the psychotic group schizophrenia was the highest followed by manic depressive psychosis, among the neurotic group HCR was the highest followed by anxiety neurosis. It is evident from this study that patients of lower and middle socio-economic group and literate group from urban areas having agricultural background are seeking modern hospital based treatment. Mentally ill patients adversely affect their families in diverse ways. There is need for appropriate policy to address the needs of families with mentally ill patients at the family and community levels. However, these must be evidence-based and this calls for further research.

\section{References}

1. The work of WHO protection and Promotion of Mental Health. WHO, GENEVA. 1990-1991:68.

2. Girolamo G de, REich J; H Personality disorder: Epidemiology of mental disorders and psychosocial problem. 3rd ed. New York: Oxford University Press:1992. p. 1-3.

3. Mental Health: A manual for primary health care physician, Institute of mental health \& Research, Dhaka, Bangladesh, 1st ed. 1993.p. 1-5,35,150.

4. Rees Linford, A new short textbook of psychiatry. 1st ed. London: Hodder Arnold: 1988.p.1-4.

5. Mia Mirjahyan MD. Socio-demographic characteristics of mental illness patients admitted in hospitals of Dhaka City. NIPSOM, Dhaka, 1995:9-12.

6. Kolb C. Lawrence: Modern Clinical psychiatry. 8th ed. Philadelphia: W.B. Saunders Company: 1973. p.1-5.

7. Ahmed S.U Analysis of the epidemiological data of 600 psychiatric patients. BMRC Bull, iv 9 (1), June, 1978:43-8.

8. Chowdhury AKMN, Alam MN Keramat SM. Desherkandi project studies - demographic morbidity \& mortality in a rural community. BMRC Bull; VII(1), June 1981:22-3.

9. Chowdhury AKMN, Selim M Sakeb N. Some aspect of psychiatric morbidity in the out patient population of a general hospital. BMRC Bull; 2(1), April 1975:51-2.

10. Alam M.N psychiatric morbidity in general practice. BMRC Bull; iv (1)1978:38-41.

11. Islam $\mathrm{H}$, Review of 5153 treated psychiatric patients. A Five year retrospective study. BMRC bull iii (1) june 1977:52-61.

12. Firoz AHM, Rahim DAA, Islam N. Pattern of psychiatric morbidity in psychiatric out patient of a general hospital. BMJ $22(1,2)$ Jan-April:29-33.

13. Karim ME, Mullick MSI, chowdhury $\mathrm{S}$, islam ME, Epidemiology of schizophrenia -Study in two urban hospital. J Inst. Post grad Med. Res 1994; 9 920:52-7.

14. Indian Council of Medical Research. Multicoated collaborative study of factors associates with the course \& outcome of schizophrenia. CMC; August,1988:4-5. 